\title{
Situs inversus totalisli bir hastada terapötik endoskopik retrograd kolanjiyopankreatografi
}

\section{Therapeutic endoscopic retrograde cholangiopancreatography in a patient with situs inversus totalis}

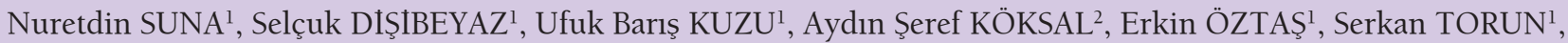
Erkan PARLAK ${ }^{2}$

${ }^{1}$ Türkiye Yüksek Ihtisas Eğitim ve Araștırma Hastanesi, Gastroenteroloji Kliniği, Ankara,

${ }^{2}$ Sakarya Üniversitesi Tip Fakültesi, Gastroenteroloji Bilim Dall, Sakarya,

Situs inversus totalis, torasik ve abdominal organların ayna hayali şeklinde yer değitirmesi ile karakterize nadir konjenital bir anomalidir. Situs inversus totalisli hastalarda safra kanalı ekseninin değișimi nedeniyle siradan bir endoskop ile teröpatik endoskopik retrograt kolanjiopankreatografi endoskopik retrograd kolanjiyopankreatografi yapmak çok daha zor olmaktadır. $\mathrm{Bu}$ yazıda, situs inversus totalisli bir hastada endoskopik retrograd kolanjiyopankreatografi işlemi olağan poziyonunda başarsız olmasına karşın sağ lateral dekübitis pozisyonda başarılı endoskopik retrograd kolanjiyopankreatografi işlemi yapılan olguyu sunuyoruz.

Anahtar kelimeler: Situs inversus totalis, koledok taşı, ERKP, çoklu metalik stent

\section{GİRİş}

Situs inversus totalis (SIT), torasik ve abdominal organların ayna hayali şeklinde yer değitirmesi ile karakterize nadir konjenital bir anomalidir. SIT, normal popülasyonda insidansı 1/8.000 ile 1/25.000'dır (1). Bu durum abdominal patolojilerin tanı ve tedavi yönetiminde zorluklara neden olabilmektedir $(2,3)$. StT'li hastalarda iç organlar sağ-sol şeklinde ters olduklarından endoskopik işlemler zor olmaktadır. Bu durumda endoskopik retrograt kolanjiyopankreatografi (ERKP) işleminde teknik değişikler gerekmektedir. Bu yazıda, SIT’li bir hastada ERKP işlemi olağan poziyonunda başarsız olmasına karşın sağ lateral dekübitis pozisyonda başarılı ERKP işlemi yapilan olguyu sunuyoruz.

\section{OLGU SUNUMU}

Olgumuz 84 yaşında erkek hasta, iki hafta önce başlayan sırta vuran epigastrik ağrı yakınması ile hastanemize başvurdu. Aynı yakınmalar son bir yılda ara ara tekralıyormuş. Hastanın SIT ve 15 yll önce kolelitiazis nedeniyle kolesistektomi öküsü mevcuttu. Fizik muayenesi kalp tepe vurusu sağda olup, palpasyonla epigastrium bölgede hassasiyet dışında normaldi. Laboratuvar incelemesinde; aspartat aminotransferaz $92 \mathrm{U} / \mathrm{l}(<40)$, alanin aminotransferaz $120 \mathrm{U} / \mathrm{L}(<41)$, gama glutamil transferaz 162 U/L (8-61), alkalen fosfataz 268 U/L

Suna N, Dişibeyaz S, Kuzu UB, et al. Therapeutic endoscopic retrograde cholangiopancreatography in a patient with situs inversus totalis. Endoscopy Gastrointestinal 2016;24:51-52
Situs inversus totalis is a rare congenital anomaly characterized by transposition of the abdominal and thoracic organs in a mirror image reversal. Therapeutic endoscopic retrograde collangiopancreatography with a regular endoscope is much more difficult due to the variation of the bile duct axis. In this article, we present a case of a successful endoscopic retrograde collangiopancreatography in a situs inversus totalis patient in the right lateral decubitus position rather than the regular position, in which the endoscopic retrograde collangiopancreatography procedure was unsuccessful.

Key words: Situs inversus totalis, endoscopic retrograde collangiopancreatography, bile duct stone

(40-130), amilaz $68 \mathrm{U} / \mathrm{L}$ (28-100), total bilirubin $0.75 \mathrm{mg} / \mathrm{dl}$ $(<1.2)$, direkt bilirubin $0.44 \mathrm{mg} / \mathrm{dl}(<0.30)$, beyaz kan hücresi $6.75 \times 10^{3} / \mu \mathrm{l}$ (3.7-9.7), C-reaktif protein $24 \mathrm{mg} / \mathrm{dl}(0-8)$, eritrosit sedimentasyon hızı $13 \mathrm{~mm} / \mathrm{saat}(0-15)$ saptandı ve diğer parametreler normaldi. SIT hastalığı akciğer grafisi ve abdomen ultrasonografi (USG) ile doğrulandı. Abdomen USG'de intrahepatik safra yolları bilateral dilate idi, koledok en geniş yerinde $15 \mathrm{~mm}$ ölçüldü ve lümende büyüğü $12 \mathrm{~mm}$ olan 3-4 adet taş ekosu alındı ve safra kesesi opere idi. ERKP işleminde normal pozisyonda duodenoskop ile girildiğinde tüm manevralara ve poziyonlara rağmen papilla görüntülenemedi. Daha sonra hasta sağ lateral deküpit pozisyonda yatırıl$\mathrm{d}_{1}$ ve sağ tarafında duodenoskop ile girildi (Resim 1). Papilla vateri uzun pozisyonda bulunabildi. Koledok selektif olarak kanülize edildi. Koledok ve intrahepatik safra yolları dilate izlendi ve koledok lümeninde büyük taşlar mevcuttu (Resim 2). Endoskopik sfinkterotomi yapıldı. Taş balonu ve basketle taşlar çıkartıldı. İşlem sırasında ve sonrasında herhangi bir komplikasyon gelişmedi.

\section{TARTISMA}

SIT, organ veya organ sistemlerinin normal lokalizasyonlarından vücudun karşı tarafına (normalin ayna görüntüsü) 
transpoze olması durumudur (4). SIT embriyonik orta barsağın saat yönünün tersine $270^{\circ}$ döneceği yerde, saat yönüne $270^{\circ}$ dönmesi ile oluşur. Bu durumda tüm torasik ve abdominal visseral organlar normalde olmaları gereken lokalizasyonun orta hatta göre simetrik lokalizasyonuna yerleşirler. Tanıda hikaye, karın ve akciğer grafisi, ultrasonografi, bilgisayarlı tomografi ve baryumlu grafi oldukça yararlıdır. Olgumuzda SIT öyküsü biliniyordu yine de ultrasonografi ve akciğer grafisi ile SIT doğrulandi.

Endoskoplar normal bir anatomik sisteme sahip kişiler için tasarlanmıştır. Endoskobun açıları kendi yönüne göre değişir. Bu nedenle konjenital anatomik varyant veya cerrahi ile değiştirilmiş gastrointestinal anatomisi olan hastalarda terapötik ERKP işleminin zorlaştığı bilinmektedir. Aynı şekilde SIT'li hastalarda safra kanalı ekseninin değişimi nedeniyle sıradan bir endoskop ile teröpatik ERKP yapmak çok daha zor olmaktadır. Bu hastalarda çeşitli teknikler kullanılarak yapılan başarılı ERKP olguları bildirilmiştir (5-11). SIT'li hastalarda anatominin sağ-sol tersliğinden kaynaklanan ERKP'nin teknik zorluğunu önlemek için, hastanın sağ lateral dekübit pozisyona alınma ve endoskopistin hastanın sağ tarafında durma tekniği ile başarılı ERKP yapılan iki olgu daha önce bildirilmiştir (12,13). Biz de olgumuzda bu tekniği kullanarak başarılı ERKP işlemini gerçekleştirdik. Işlem sırasında ve sonrasında komplikasyon gelişmedi. Sonuç olarak SIT hastalarında bu yöntemin güvenli, pratik ve ilk tercih edilmesi gereken yöntem olduğunu düşünüyoruz.

\section{KAYNAKLAR}

1. Lee SE, Kim HY, Jung SE, et al. Situs anomalies and gastrointestinal abnormalities. J Pediatr Surg 2006;41:1237-42

2. Uemura S, Maeda $H$, Munekage $M$, et al. Hepatic resection for metastatic colon cancer in patients with situs inversus totalis complicated by multiple anomalies of the hepatobiliary system: the first case report. J Gastrointest Surg 2009;13:1724-7.

3. Blegen HM. Surgery in situs inversus. Ann Surg 1949;129:244-59.

4. Sands SS, Taylor JF. Prescreen evaluation of situs inversus patients. Int Surg 2001;86:254-8.

5. McDermott JP, Caushaj PF. ERCP and laparoscopic cholecystectomy for cholangitis in a 66-year-old male with situs inversus. Surg Endosc 1994;8:1227-9.

6. Venu RP, Geenen JE, Hogan WJ et al. ERCP and endoscopic sphincterotomy in patients with situs inversus. Gastrointest Endosc 1985;31:33840 .

7. $\mathrm{Hu} \mathrm{B}$, Wang $\mathrm{CH}$, Chen $\mathrm{P}$, et al. Acute cholangiopancreatic diseases with situs inversus totalis treated with endoscopic sphincterotomy: Report of two cases. J Dig Dis 2009;10:71-3.
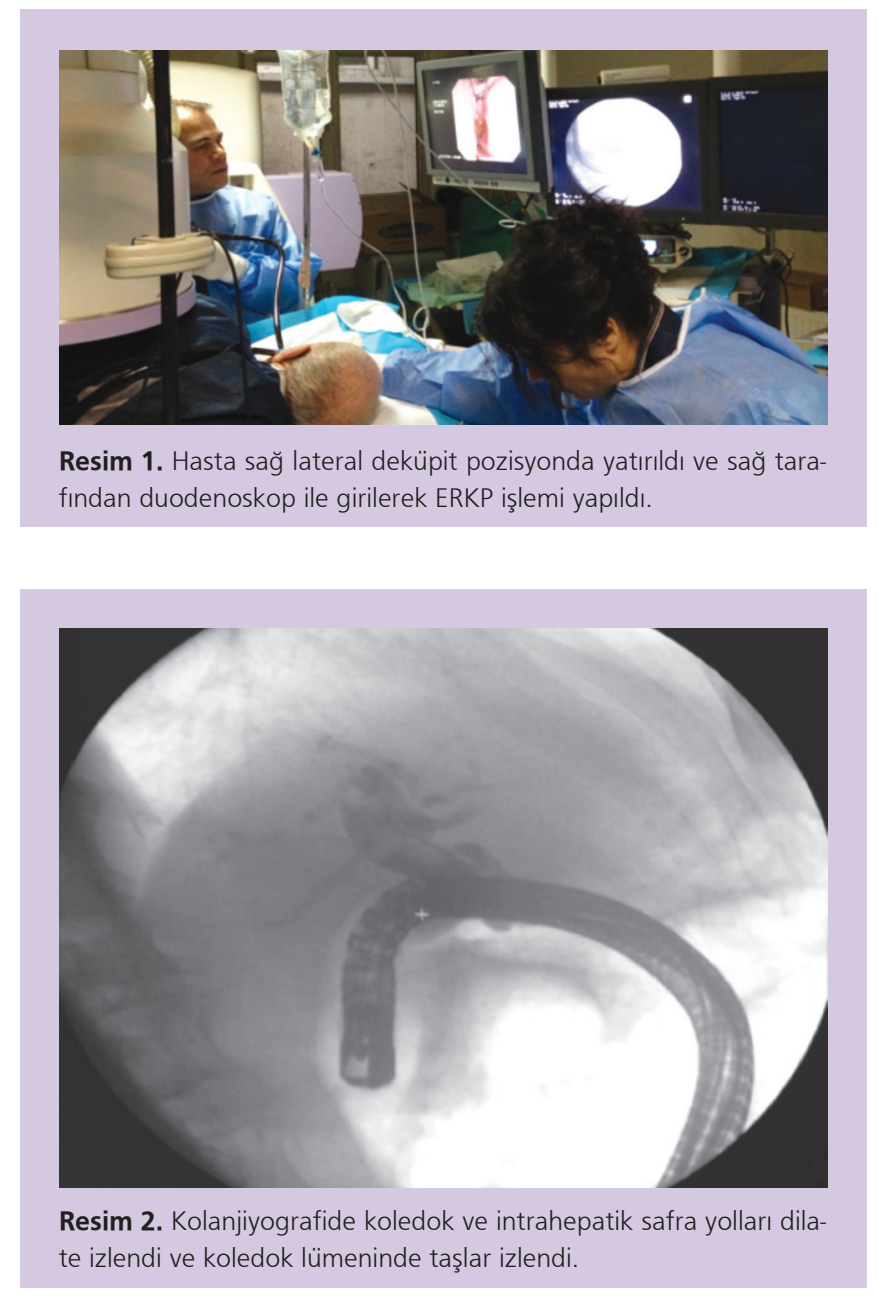

8. Benhammane H, Kharmoum S, Terraz S. Common bile duct adenocarcinoma in a patient with situs inversus totalis: report of a rare case. BMC Res Notes 2012;5:681

9. Fiocca F, Donatelli G, Ceci V, et al. ERCP in total situs viscerum inversus. Case Rep Gastroenterol 2008;2:116-20.

10. García-Fernández FJ, Infantes JM, Torres Y, et al. ERCP in complete situs inversus viscerum using a "mirror image" technique. Endoscopy 2010;42(Suppl 2):E316-7.

11. de la Serna-Higuera C, Perez-Miranda M, Flores-Cruz G, et al. Endoscopic retrograde cholangiopancreatography in situs inversus partialis. Endoscopy 2010;42(Suppl 2):E98.

12. Lipschutz JH, Canal DF, Hawes RH, et al. Laparoscopic cholecystectomy and ERCP with sphincterotomy in an elderly patient with situs inversus. Am J Gastroenterol 1992;87:218-20.

13. Nordback I, Airo I. ERCP and endoscopic papillotomy in complete abdominal situs inversus. Gastrointest Endosc 1988;34:150. 